\title{
Breeding strategies and advances in line selection for Fusarium head blight resistance in wheat
}

\author{
Barbara Steiner $^{1}$ • Maria Buerstmayr ${ }^{1} \cdot{\text { Sebastian } \text { Michel }^{1} \text { - Wolfgang Schweiger }}^{1}$. \\ Marc Lemmens ${ }^{1} \cdot$ Hermann Buerstmayr ${ }^{1}$
}

Received: 9 August 2016 / Accepted: 12 January 2017 /Published online: 21 February 2017

(C) The Author(s) 2017. This article is published with open access at Springerlink.com

\begin{abstract}
Fusarium head blight (FHB) is a fungal disease of worldwide importance to small grain cereals that may lead to severe losses in both yield and quality. The development of resistant varieties is the most effective approach for managing the disease. Genetic variation for FHB resistance is large, including 'exotic' and 'native' wheat germplasm. Methods for selecting improved lines include: 1) phenotypic selection with direct symptom evaluation; 2) marker-assisted selection for well-characterized QTL and 3) genomic selection employing genome-wide prediction models. Breeding programs need to find the optimal deployment of the complementary approaches according to their available facilities, resources and requirements. This review aims to summarize recent advances in FHB resistance breeding, thereby discussing the importance of morphological traits like the extent of retained anthers after flowering, its suitability for indirect selection and the pronounced association of the semi-dwarfing allele $R h t-D 1 b$ with increased anther retention and FHB severity. Markerassisted selection is successfully applied to select for largeeffect QTL, especially for the most prominent resistance QTL Fhb1 in bread wheat, as well as in durum wheat as recently demonstrated. The resistance locus Fhbl has been partly elucidated, a pore-forming toxin-like gene confers resistance against fungal spread. Genomic selection for FHB resistance appears promising especially for breeding programs
\end{abstract}

Section Editor: Emerson M. Del Ponte

Barbara Steiner

barbara.steiner@boku.ac.at

1 Institute of Biotechnology in Plant Production (IFA-Tulln), BOKU University of Natural Resources and Life Sciences, Vienna, Konrad Lorenz Strasse 20, A-3430 Vienna, Tulln, Austria deploying 'native' resistance sources with many small-effect QTL.

Keywords Fusarium head blight - Triticum aestivum . Molecular breeding · Mycotoxin · Resistance breeding · Selection

\section{Introduction}

Fusarium head blight (FHB) is one of most destructive diseases of bread wheat (Triticum aestivum L.) and durum wheat (Triticum durum Desf.) worldwide, which leads to significant losses in grain yield and quality. The disease is primarily caused by members of the Fusarium graminearum sensu lato but also by $F$. culmorum and $F$. avenaceum in cooler region (Parry et al. 1995). Most importantly, these fungi are able to produce mycotoxins that accumulate in the grains and constitute a serious threat to food safety (Pestka 2010). Among them, the type-B trichothecenes such as deoxynivalenol (DON) or nivalenol as well as the resorcyclic acid lactone zearalenone are the most commonly found in commercial grain (Goswami and Kistler 2004).

The frequency of FHB epidemics has increased in recent years in most of the major wheat production regions worldwide. Changes in crop management practices, such as minimum or reduced tillage and the intensification of maize in crop rotations promote disease incidences (McMullen et al. 2012). Additionally, increasing humidity and warm temperatures during the anthesis are optimal conditions for FHB outbreaks (Juroszek and Tiedemann 2015).

The use of resistant cultivars is the most effective tool for controlling FHB. The success of breeding programs aiming at resistant genotypes is largely dependent on the availability of resistant germplasm, genetic variation in breeding 
populations, and methods to reliably estimate the resistance level of the breeding lines enabling efficient selection of improved individuals. This review summarizes recent findings in FHB resistance breeding, discusses the available options for selection and trait associations.

\section{Resistance sources and QTL}

In hexaploid wheat, genetic variation for FHB resistance is considered large and a range of resistance sources are known, including both 'exotic' and 'native' wheat germplasm. In particular, Asian sources are used as resistance donors worldwide, such as the Chinese spring wheat variety 'Sumai-3' (Buerstmayr et al. 2009). Resistance to FHB is a quantitatively inherited trait influenced by environmental factors with significant genotype-by-environment interactions. Numerous quantitative trait loci (QTL) have been identified for bread wheat distributed over all 21 wheat chromosomes. However, only a handful of QTL has been validated across studies and is successfully employed in breeding programs worldwide (Buerstmayr et al. 2009; Liu et al. 2009; Löffler et al. 2009). Among these, the strongest and best-validated resistance QTL were identified in Chinese germplasm: Fhb1, Fhb2, and Qfhs.ifa-5A, all derived from 'Sumai-3' (Waldron et al. 1999; Bai et al. 1999; Anderson et al. 2001; Buerstmayr et al. 2002; 2003a, b). Further resistance sources include the QTL Fhb4 and Fhb5 found in 'Wangshiubai' (Xue et al. 2010, 2011) and Qfhs.nau-2DL identified in the breeding line CJ9306 (Jiang et al. 2007a, b). In addition, Fhb7 was recently detected in the wild species Thinopyrum ponticum (Guo et al. 2015).

Several types of FHB resistance have been described and proposed in relation with FHB characteristics (Schroeder and Christensen 1963; Mesterházy 1995; Ban 2000; Buerstmayr and Lemmens 2015). Among these, resistance to initial infection (type 1) and resistance to fungal spread within the infected spikes (type 2) are the two main types that contribute to 'field resistance' and have been more commonly evaluated in QTL mapping studies. The large effect QTL, such as Fhb1 and Qfhs.nau-2DL confer resistance to both fungal spread (type 2) and to toxin accumulation. In addition $F h b 1$ enhances the ability to convert DON into the less toxic DON-3glucoside indicating a role in detoxification (Lemmens et al. 2005). Qfhs.ifa-5A contributes mainly to type 1 resistance and low toxin accumulation. The majority of QTL detected for FHB severity on the heads (type 1 and 2 combined) or damaged grains coincidence with QTL for mycotoxin content. Only few examples indicate that plant genes may exist which have a function in detoxification, but are not associated with FHB severity (Buerstmayr et al. 2009; Buerstmayr and Lemmens 2015).
In durum wheat FHB resistance breeding is hampered by the limited genetic variation within the species (Prat et al. 2014). Only five moderately type 2 resistant Tunisian lines were identified in an international collection of 7,500 T. durum lines comprising accessions from CIMMYT and ICARDA (Elias et al. 2005; Huhn et al. 2012). The scarce resistance coincides with the exclusive use of durum wheat for human consumption, which puts durum production under risk. More distantly related wild and cultivated relatives, e.g. $T$. dicoccoides, $T$. dicoccum and T. carthlicum, were screened to broaden the base of resistant sources for durum wheat (2003a, 2003a, b; Oliver et al. 2007, 2008), but resistances found therein do not come close to the strong QTL detected in hexaploid wheat (Prat et al. 2014; Zhang et al. 2014; Zhu et al. 2016b).

\section{Screening tools and methods}

In general, plant breeding relies upon the generation of new genetic variation, screening of the available diversity and the subsequent selection of superior individuals. For FHB resistance breeding, populations need to be generated from crosses with at least one moderately to highly resistant parent to obtain progeny with acceptable resistance levels. The most common screening/selection approach for FHB resistance involves the induction of epidemics and directly evaluation of the resistance level of the lines. Such approach, which is based on phenotypic assessments by means of visual assessments, has been the only option for a long time that led to enhanced levels of resistance in commercial cultivars. With the advent of molecular markers and new statistical methods, additional tools have been established for plant breeders that partially overcome the limitations of an exclusive phenotypic-based selection. For these genotypic selection methods, marker-assisted and genomic selection, the prediction of FHB resistance levels and the selection of improved individuals are based on genetic fingerprints. The key milestones in breeding for FHB resistance over the years, with more emphasis to the last 15 years, are summarized in Fig. 1.

\section{Phenotypic selection}

A reliable phenotyping method should allow estimating genetically determined resistance from each line of a breeding population as precisely as possible. Phenotypic selection for FHB resistance is usually practiced in more or less advanced generations e.g. from $\mathrm{F}_{4}$ onwards in separate resistance testing nurseries. This method is labor and time-intensive due to significant environment and genotype-by-environment interaction effects. It also requires artificial inoculation systems to ensure homogeneous disease intensity levels in field trials 


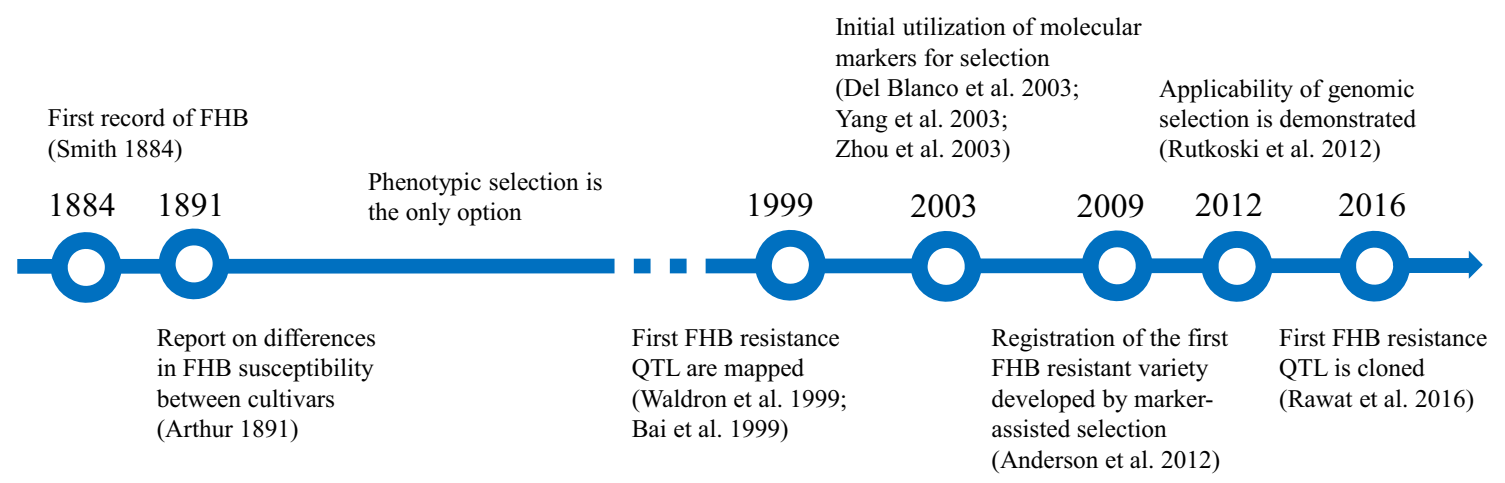

Fig. 1 Milestones in breeding for FHB resistance in a temporal perspective

(Miedaner et al. 2001; Dill-Macky 2003). Breeders are managing several hundreds of lines in their breeding programs each year. To manage large-scale screenings, rapid and easy to assess disease-related variables such as percentage of diseased heads (disease incidence) or spikelets (disease severity), which can be visually assessed before harvest, are often used in applied plant breeding programs. Apart from scorings in the field, post-harvest kernel samples can also be analyzed for disease symptoms. Usually this is done either by visual scoring or digital image analysis (Maloney et al. 2014) of the percentage of diseased grains in harvested samples or by measuring yield (or yield components) relative to non-inoculated controls (Dill-Macky 2003). A low mycotoxin concentration in the harvested kernels is most important, but measuring mycotoxin content is both time-consuming and expensive. Most often, mycotoxin analyses are restricted to a reduced number of advanced lines to validate both the gain in resistance to FHB and mycotoxin accumulation via breeding. Many reports reveal strong associations between disease severity estimates and toxin contents, suggesting that selection for low FHB severities on heads and/or grains results in reduced toxin contamination (Buerstmayr and Lemmens 2015).

\section{Morphological and phenological traits}

Trait associations play an important role in Fusarium resistance, particularly for 'field'resistance. Several morphological and phenological traits have been found to strongly correlate with FHB resistance, and many resistance QTL overlap with QTL for such traits (Buerstmayr et al. 2009). Among these, plant height and the extent of retained anthers after flowering play a major role (Buerstmayr et al. 2012). Many studies report on the relationship between plant height and FHB resistance - in general, the shorter the plants the more severe are FHB epidemics (Mesterhazy 1995; Hilton et al. 1999; Buerstmayr et al. 2009; Mao et al. 2010). The semi-dwarfing alleles $R h t-D 1 b$ and $R h t-B 1 b$ are widely deployed in wheat breeding and both alleles show similar effects on reducing plant height but differ in their impact on FHB resistance.
Rht-D1b on chromosome 4D is strongly associated with reduced resistance to initial infection, while the role of the homoeologous allele Rht-B1b on chromosome 4B is less clear (Draeger et al. 2007; Holzapfel et al. 2008; Srinivasachary et al. 2008, 2009; Voss et al. 2008; Miedaner et al. 2011).

Floral traits also play a critical role in FHB infection. Narrow and short floral opening increases FHB resistance (Gilsinger et al. 2005) just as cleistogamy (Kubo et al. 2010). In addition, anthers and pollen partially trapped within the spikelet stimulate fungal growth and disease establishment compared to lines with rapid and complete anther extrusion. This relationship has been found and commented almost 100 years ago (Dickson et al. 1921; Pugh et al. 1933) and resurged recently as a focus of several research groups (Skinnes et al. 2008, 2010; Graham and Browne 2009; Kubo et al. 2013; Lu et al. 2013; He et al. 2014; Buerstmayr and Buerstmayr 2015, 2016). Molecular-genetic analysis revealed a quantitative nature of anther retention/extrusion and detected the genetic basis for the phenotypic correlations with FHB traits. In the moderately resistant Swiss cultivar Arina two resistance QTL coincidence with QTL for anther extrusion (Buerstmayr and Buerstmayr 2015) and in a cross of the CIMMYT line SHA3/CBRD by the German variety Naxos all five QTL for anther extrusion overlapped with QTL for FHB resistance ( $\mathrm{Lu}$ et al. 2013). The association of anther extrusion and FHB resistance was not just found in specific mapping populations but also in current wheat breeding material from Austria and France (Steiner et al. unpublished).

The above mentioned effects of the semi-dwarfing loci Rht$B 1$ and Rht-D1 on plant height, FHB severity and anther retention were analyzed simultaneously in a recent study by Buerstmayr and Buerstmayr (2016). Both semi-dwarfing alleles $R h t-B 1 b$ and $R h t-D 1 b$ reduced plant height and increased the proportion of retained anthers and were associated with increased FHB severity. Notably, the Rht-Dlb allele had a more significant effect on anther retention and FHB severity than the Rht-B1b allele suggesting that differences in disease severity associated with the two semi-dwarfing alleles can be partly explained by their different effect on anther extrusion. A partly common genetic control of anther extrusion and plant 
height was also found by Lu et al. (2013). In that study, QTL common for both traits were associated with FHB resistance and interestingly one of the loci was Rht-Bl. Whether these relationships are due to pleiotropic effects of the $R h t$ alleles on plant height and anther retention or are caused by linked genes remains to be clarified. As a consequence for FHB resistance breeding: the semi-dwarf allele $R h t-B 1 b$ should be preferred over Rht-Dlb.

The findings highlight especially anther extrusion as relevant morphological trait that needs to be considered in FHB resistance breeding. As it is a highly heritable trait (Langer et al. 2014; Buerstmayr and Buerstmayr 2015), visual selection for rapid and complete anther extrusion appears promising for cost-effective indirect selection to enhance FHB resistance.

\section{Marker-assisted selection}

Selection based on molecular marker patterns associated with known resistance QTL is termed marker-assisted selection (MAS). Its value for improving FHB resistance has been confirmed by many research studies and several success stories from breeding programs implementing MAS have been published (Del Blanco et al. 2003; Yang et al. 2003; Zhou et al. 2003; Miedaner et al. 2006; Anderson et al. 2007a, 2007b; McCartney et al. 2007; Wilde et al. 2007; Von der Ohe et al. 2010; Salameh et al. 2011; Agostinelli et al. 2012; Balut et al. 2013).

Prerequisites for effective MAS are resistance QTL with relatively large and stable effects and the availability of tightly linked markers. Numerous QTL mapping studies have identified the few major QTL Fhb1, Fhb2, Fhb4, Fhb5, Fhb7, Qfhs.ifa-5A, Qfhs.nau-2DL (Buerstmayr et al. 2009; Liu et al. 2009; Löffler et al. 2009). For Fhb1 the nearly diagnostic marker UMN10 (Liu et al. 2008) is available, which is used worldwide in many wheat breeding programs for markerassisted introgression of Fhbl (Buerstmayr et al. 2009, 2015). Recently, UMN10 was complemented by a userfriendly KASP marker derived from the sequenced UMN10 PCR product (Schweiger et al. 2016). For other resistance QTL markers flanking the QTL region are employed and for Fhb7, a major QTL derived from Thinopyrum ponticum, translocation lines with shortened alien segments and closely linked markers were developed (Guo et al. 2015).

MAS for major QTL efficiently improved the FHB resistance level in adapted, high-yielding wheat germplasm; even in winter wheat breeding programs, where breeders are cautious in introducing 'exotic' spring wheat resistance sources such as Sumai-3 (Miedaner et al. 2006; Wilde et al. 2007; Von der Ohe et al. 2010; Salameh et al. 2011; Agostinelli et al. 2012; Balut et al. 2013). This enabled the selection of lines with clearly improved resistance level while keeping the yield potential at the level of the recurrent parent. Differences in agronomic and quality traits were small, although sometimes significantly lower (Von der Ohe et al. 2010; Salameh et al. 2011; Balut et al. 2013). In some populations pyramiding of different resistance QTL resulted in enhanced FHB resistance (Miedaner et al. 2006), while in other crosses the introgression of a second QTL did not significantly improve the resistance level (Von der Ohe et al. 2010). Shi et al. (2008) accumulated in the highly resistant resource WSY several resistance genes from three different resistant germplasm (Sumai-3, Wangshuibai and Nobeokabouzu) constituting valuable material for FHB resistance breeding. The effectiveness of MAS was also demonstrated for moderately strong 'native' European winter wheat resistance QTL (Häberle et al. 2007).

In a direct comparison of marker-based selection for $F h b 1$ and QFhs.nau-2DL versus phenotypic selection both methods were equally suitable to select the most resistant lines. The authors proposed an initial round of phenotypic selection at moderate selection intensity to enrich the population with major resistance alleles while preserving variation at minor resistance loci followed by genotyping for resistance alleles at the major QTL (Agostinelli et al. 2012).

Eckard et al. (2015) conducted mapping, validation and marker-assisted pyramiding of resistance QTL simultaneously in early generation breeding populations using identical-bydescent-based linkage analysis. This approach facilitates fast and direct application of QTL mapping results.

In conclusion, phenotypic selection and MAS can substantially improve FHB resistance to similar levels; for markerbased introgression selection gain per unit time is increased (Wilde et al. 2007).

Communication with wheat breeders about the practical deployment of the major resistance QTL revealed that in North America Fhbl and to a lesser extent Qfhs.ifa-5A are used in practical breeding and $F h b 1$ is present in several of the registered cultivars. From the University of Minnesota spring wheat breeding program $50 \%$ of the wheat varieties carry $F h b 1$ and about 2/3 of their advanced breeding lines, while $Q f h s$.ifa- $5 A$ is present at a lower frequency of 5-10\% (J. Anderson, personal communication). In Europe mainly 'native' resistance sources are exploited resulting in only one registered cultivar carrying $F h b 1$, the French cultivar Jaceo (Syngenta Seeds). Linkage drag of the major Chinese resistance QTL hamper their deployment in modern cultivars, for example increased lodging and decreased yield were observed (E. Ebmeyer, personal communication), whereas lines with acceptable resistance levels can also be developed through the accumulation of several small-effect QTL as present in the native gene pools (E. Ebmeyer, K. Glover, M. Sorrells, personal communication).

At CIMMYT resistance alleles from Chinese varieties were already introgressed into breeding lines in the 1980 s. Currently, QTL 2DLc (Lu et al. 2013), Fhb4 and Fhb5 are the most frequently found major QTL in CIMMYT FHB 
screening nurseries that are mainly conferring type 1 resistance (He et al. 2013a, b, 2016; Osman et al. 2015). The major type 2 resistance QTL Fhb1 was gradually lost in CIMMYT lines because of its tightly repulsive linkage with the durable stem rust gene $S r 2$, which is indispensable at CIMMYT. Recombinant lines with $F h b 1$ and $S r 2$ in coupling linkage phase have been developed and will be used to increase FHB resistance (He et al. 2015; Zhang et al. 2016).

\section{Improvement of FHB resistance in durum wheat}

Given the successful MAS studies in hexaploid wheat, it appeared straightforward to introgress major QTL from hexaploid wheat into durum wheat. Attempts to transfer QTL had limited success, causing speculations about the presence of resistance suppressors in durum wheat and the importance of the D subgenome for establishing resistance (Kishii et al. 2005; Fakhfakh et al. 2011; Zhu et al. 2016a).

A recent study (Prat et al. 2016) reported the successful introgression of Fhbl from hexaploid wheat into T. durum resulting in improved resistance. The effect of Fhbl from Sumai-3 has been assessed in three durum wheat crosses between an Fhbl harbouring experimental T. durum line and three European T. durum cultivars. Fhbl was detected in all three resulting populations explaining between 5 and $16 \%$ of the phenotypic variance for FHB severity, depending on the genetic background. Although the semi-dwarfing Rht-B1 locus regulating plant height had a strong effect in modulating FHB severity in these populations, the negative effect of the semi-dwarf allele $R h t-B 1 b$ on FHB resistance was largely compensated in lines carrying also Fhbl. The efficient implementation of Fhbl into durum wheat represents a major achievement in resistance breeding, and the novel germplasm will be highly beneficial for Fusarium resistance breeding in durum wheat.

\section{Genomic selection}

MAS is effective for QTL with intermediate to large effects, but many of the genes contributing to FHB resistance have small effects especially those derived from non-Chinese sources (Buerstmayr and Lemmens 2015; Mirdita et al. 2015; Hoffstetter et al. 2016a). Genomic selection (GS) is an alternative/complementary method of genotypic selection. It can support breeding of complex quantitative traits by estimating genome-wide marker effects for many markers simultaneously in a phenotyped training population, and use these for predicting genomic estimated breeding values of non-phenotyped individuals in a selection population. Selection can be performed ahead of cost-intensive phenotypic tests, thus potentially shortening the breeding cycle and increasing the gain by selection per unit time.
A strong advantage of GS compared to MAS is that all of the QTL present in the primary gene pool of wheat can be exploited, which was beforehand merely feasible by phenotypic selection (Heffner et al. 2009; Bassi et al. 2016). The applicability of GS for FHB resistance breeding has been demonstrated by a few studies identifying several factors influencing the prediction accuracies including the number of resistance QTL, their effects and interactions; type of FHB resistance trait and its heritability; size and relatedness of the breeding population and the training population; choice of statistical model; marker platform and marker density (Rutkoski et al. 2012; Arruda et al. 2015, 2016; Jiang et al. 2015; Mirdita et al. 2015; Hoffstetter et al. 2016b).

GS has usually higher prediction accuracy than MAS, with some dependency on the studied FHB resistance trait, the used resistance sources and the population size. Two studies with rather small population sizes revealed surprisingly high prediction accuracies for MAS in comparison to GS (Rutkoski et al. 2012; Jiang et al. 2015). In a population harboring Fhbl and other major resistance QTL MAS even outperformed GS in prediction accuracy for DON content. For other FHB resistance traits genomic predictions based on all markers were superior indicating that in the specific population DON resistance is mainly controlled by few major QTL compared to the other FHB related traits (Rutkoski et al. 2012).

GS models able to capture non-additive effects were often the more accurate methods, suggesting epistatic interactions of the underlying resistance genes (Rutkoski et al. 2012; Mirdita et al. 2015). Exploiting prior information on correlated traits and major QTL improved accuracies (Rutkoski et al. 2012; Arruda et al. 2016; Hoffstetter et al. 2016b), just as using a marker-based instead of pedigree-based relationship matrix (Arruda et al. 2015). Marker density affected prediction accuracies only marginally on the other hand: Arruda et al. (2015) observed a strong decrease of prediction accuracies only when the marker number decreased below 3000. Consequently, GS for FHB resistance can be implemented most cost-efficiently based on low- to mediumdensity genome coverage (Arruda et al. 2015; Jiang et al. 2015). Hoffstetter et al. (2016b) suggested using subsets of training population lines and markers for generating GS models with improved accuracy and proposed the development of alternative genotyping platforms for the marker subsets that are less expensive and more repeatable than genome-wide genotyping techniques.

The so far most extensive study analyzed 2325 European winter wheat lines. Association mapping detected no large effect QTL, resulting in only low prediction accuracies for FHB resistance obtained by cross-validation with values not passing 0.2 , whereas for GS models the prediction accuracy was high and amounted to 0.6 (Mirdita et al. 2015). Generally, moderate to high prediction accuracies were observed for FHB resistance, suggesting GS as a very promising breeding strategy especially for breeding programs deploying 'native' resistance sources. 


\section{Identification of the genes behind the QTL}

Knowledge of the genes underlying QTL is of great interest to biologists and has potential benefit for plant breeding. Yet functional validation of candidate genes remains challenging in wheat due to genome size and polyploidy. Fhbl is the target of the most advanced positional cloning projects. BAC sequencing of the QTL region in the susceptible wheat reference cultivar Chinese Spring did not reveal the causal gene behind Fhb1 (Liu et al. 2008). Recently the QTL region has been resolved for the highly resistant CIMMYT line CM-82036 showing substantial deviates from the Chinese Spring reference in size and gene content. Repressed recombination at the locus complicated fine-mapping and highlighted 28 putative candidate genes (Schweiger et al. 2016). Of these, a gene encoding a chimeric lectin with agglutinin domains and a pore-forming toxin-like domain has been identified as the causal gene behind spreading resistance (type 2) by mutation analysis, gene silencing and transgenic overexpression. The authors demonstrate that the gene does not confer resistance against DON suggesting that toxin resistance is under different genetic control in the same genetic block (Rawat et al. 2016). For several other resistance QTL fine-mapping and cloning approaches are underway, which will result in the development of diagnostic markers for resistance QTL to be easily adopted by breeders (Cuthbert et al. 2007; Xue et al. 2010, 2011; Zhu et al. 2016b).

\section{The masked mycotoxin problem}

Metabolisation of mycotoxins in planta yields so called 'masked' mycotoxins, which are not routinely analyzed, but remain hazardous since endogenous hydrolases may cleave the compound and reactivate the toxin (Rychlik et al. 2014). Several conjugated forms of DON such as DON-3-glucoside (Poppenberger et al. 2003) and DON sulfates (Warth et al. 2015), but also of zearalenone and fumonisins have been identified to date (De Saeger and Van Egmond 2012; Berthiller et al. 2013).

The prominent resistance QTL Fhb1 is associated with resistance to fungal spread and the ability to inactivate DON. Lemmens et al. (2005) reported that Fhbl enhances the ability to convert DON into DON-3-glucoside, initiating discussions on possible hidden risks when introgressing this QTL into wheat cultivars because a considerable fraction of the mycotoxin content might be just masked as glucoside but not circumvented from production. A recent review including experimental data from five field trials summaries the effect of FHB resistance breeding in wheat on DON and DON-3glucoside levels (Lemmens et al. 2016). All wheat lines have the ability to convert DON to DON-3-glucoside, independent from their specific FHB resistance level confirming that detoxification of DON to DON-3-glucoside is not a new trait introduced by recent resistance breeding efforts. Several independent experiments revealed high correlations of FHB symptoms on wheat heads, DON and DON-3-glucoside contents showing that selecting improved lines based on FHB symptoms or DON reduces simultaneously the DON-3-glucoside contamination (Audenaert et al. 2013; Dall'Asta et al. 2013; Lemmens et al. 2016). The amount of DON-3-glucoside relative to DON contamination varied between 5 and $30 \%$ and was influenced by genotypes and environments. Notably the most FHB resistant lines showed the lowest contamination with DON and with DON-3 glucoside, but relatively more DON was glycosylated (up to $30 \%$ ) compared to susceptible cultivars (Berthiller et al. 2009; Dall'Asta et al. 2013; Lemmens et al. 2016). Specific resistance QTL (e.g. Fhbl) possibly enhance the speed or rate of DON detoxification. Transgenic wheat expressing the barley DON-inactivating UDP-glycosyltransferase Hv13248 exhibited high level of FHB resistance, ultimately by the faster inactivation of the toxin (Li et al. 2015).

Taken together, while masked mycotoxins remain an additional considerable threat in harvests contaminated with DON close to tolerable limits, resistance mechanisms that may also rely on the successful (early) inactivation of the toxin are desirable traits as disease development comes to an early halt with the successful inactivation of the toxin in planta. Hence, overall much lower levels of DON and DON-3 glucoside are recorded.

\section{Final remarks and future directions}

Breeding for FHB resistance is resource-demanding due to environment effects and genotype-by-environment interactions. Several options for resistance selection are feasible: phenotypic selection based on symptom evaluation in field or greenhouse experiments, MAS for well characterized QTL and GS using genome-wide prediction models. Irrespective of selection method, precise and accurate phenotypes are the cornerstone of any successful breeding for FHB resistance. While genotyping methods advanced rapidly, providing genome-wide marker coverage at reasonable prices, high-throughput and cost-efficient phenotyping technologies are lagging behind. Several approaches and tools for precision phenotyping are under investigation to bring these techniques into the breeder's field.

In addition, several morphological and phenological traits are associated with FHB resistance, which need further evaluation and consideration. Among these, anther extrusion seems to be very important. Selection for high anther extrusion results in increased resistance to initial infection. Floral and flowering traits in wheat have recently received increased interest from the breeders because of hybrid breeding for which improved outcrossing in the male pool is of utmost importance. Fast and reliable screening techniques are 
available which can easily be implemented in resistance breeding programs.

Marker-assisted selection for major QTL is a successful strategy for rapid resistance improvement. Ongoing QTL cloning approaches will provide diagnostic markers for resistance genes for more efficient selection in applied breeding programs. For the establishment of highly resistant lines breeders are not just restricted to major QTL identified in Chinese germplasm, also in native resistance sources from e.g. Europe and North America lines with good resistance levels can be selected. The common practice to pyramid minor QTL by phenotypic selection can be accelerated with genomic selection. In order to be adopted by farmers, FHB resistance cannot be treated as an isolated trait, but rather needs to be incorporated in regionally adapted and productive cultivars. This requires continuous investments in crop breeding. FHB resistant cultivars prevent the mycotoxin problem right at the beginning of the cereal food chain: at the farmer's field. Therefore, developing FHB resistant and productive cultivars is a sustainable, environmentally friendly, and cost-effective approach towards increasing food and feed safety and security.

Acknowledgments Open access funding provided by University of Natural Resources and Life Sciences Vienna (BOKU).

Open Access This article is distributed under the terms of the Creative Commons Attribution 4.0 International License (http:// creativecommons.org/licenses/by/4.0/), which permits unrestricted use, distribution, and reproduction in any medium, provided you give appropriate credit to the original author(s) and the source, provide a link to the Creative Commons license, and indicate if changes were made.

\section{References}

Agostinelli AM, Clark AJ, Brown-Guedira G, Van Sanford DA (2012) Optimizing phenotypic and genotypic selection for Fusarium head blight resistance in wheat. Euphytica 186:115-126

Anderson JA (2007) Marker-assisted selection for Fusarium head blight resistance in wheat. Int J Food Microbiol 119:51-53

Anderson JA, Stack RW, Liu S, Waldron BL, Fjeld AD, Coyne C, Moreno-Sevilla B, Fetch JM, Song QJ, Cregan PB, Frohberg RC (2001) DNA markers for Fusarium head blight resistance QTLs in two wheat populations. Theor Appl Genet 102:1164-1168

Anderson JA, Chao SM, Liu SX (2007) Molecular breeding using a major QTL for fusarium head blight resistance in wheat. Crop Sci 47:112-119

Anderson JA, Wiersma JJ, Linkert GL, Kolmer JA, Jin Y, Dill-Macky R, Wiersma JV, Hareland GA (2012) Registration of 'Sabin' Wheat. J Plant Registrations 6:174-179

Arruda MP, Brown PJ, Lipka AE, Krill AM, Thurber C, Kolb FL (2015) Genomic selection for predicting fusarium head blight resistance in a wheat breeding program. Plant Genome 8:1-12

Arruda MP, Lipka AE, Brown PJ, Krill AM, Thurber C, Brown-Guedira G, Dong Y, Foresman BJ, Kolb FL (2016) Comparing genomic selection and marker-assisted selection for Fusarium head blight resistance in wheat (Triticum aestivum L.). Mol Breed 36:84

Arthur JC (1891) Wheat scab. Indiana Agric Exp Station Bull 36:129-132
Audenaert K, De Boevre M, Vanheule A, Callewaert J, Bekaert B, Hofte M, De Saeger S, Haesaert G (2013) Mycotoxin glucosylation in commercial wheat varieties: Impact on resistance to Fusarium graminearum under laboratory and field conditions. Food Control 34:756-762

Bai GH, Kolb FL, Shaner G, Domier LL (1999) Amplified fragment length polymorphism markers linked to a major quantitative trait locus controlling scab resistance in wheat. Phytopathology 89: 343-348

Balut AL, Clark AJ, Brown-Guedira G, Souza E, Van Sanford DA (2013) Validation of Fhb1 and QFhs.nau-2DL in Several Soft Red Winter Wheat Populations. Crop Sci 53:934-945

Ban T (2000) Analysis of quantitative trait loci associated with resistance to Fusarium head blight caused by Fusarium graminearum schwabe and of resistance mechanisms in wheat (Triticum aestivum L.). Breed Sci 50:131-137

Bassi FM, Bentley AR, Charmet G, Ortiz R, Crossa J (2016) Breeding schemes for the implementation of genomic selection in wheat (Triticum spp.). Plant Sci 242:23-36

Berthiller F, Dall'asta C, Corradini R, Marchelli R, Sulyok M, Krska R, Adam G, Schuhmacher R (2009) Occurrence of deoxynivalenol and its 3-D-glucoside in wheat and maize. Food Addit Contaminants Part aChemistry Analysis Control Exposure Risk Assess 26:507-511

Berthiller F, Crews C, Dall'Asta C, De Saeger S, Haesaert G, Karlovsky P, Oswald IP, Seefelder W, Speijers G, Stroka J (2013) Masked mycotoxins: a review. Mol Nutr Food Res 57:165-186

Buerstmayr M, Buerstmayr H (2015) Comparative mapping of quantitative trait loci for Fusarium head blight resistance and anther retention in the winter wheat population Capo $\times$ Arina. Theor Appl Genet 128:1519-1530

Buerstmayr M, Buerstmayr H (2016) The semi-dwarfing alleles Rht-Dlb and $R h t-B 1 b$ show marked differences in their associations with anther-retention in wheat heads and with Fusarium head blight susceptibility. Phytopathology. doi:10.1094/PHYTO-05-16-0200-R

Buerstmayr H, Lemmens M (2015) Breeding healthy cereals: genetic improvement of Fusarium resistance and consequences for mycotoxins. World Mycotoxin J 8:591-602

Buerstmayr H, Lemmens M, Hartl L, Doldi L, Steiner B, Stierschneider M, Ruckenbauer P (2002) Molecular mapping of QTLs for Fusarium head blight resistance in spring wheat. I. Resistance to fungal spread (type II resistance). Theor Appl Genet 104:84-91

Buerstmayr H, Steiner B, Hartl L, Griesser M, Angerer N, Lengauer D, Miedaner T, Schneider B, Lemmens M (2003a) Molecular mapping of QTLs for Fusarium head blight resistance in spring wheat. II. Resistance to fungal penetration and spread. Theor Appl Genet 107:503-508

Buerstmayr H, Stierschneider M, Steiner B, Lemmens M, Griesser M, Nevo E, Fahima T (2003b) Variation for resistance to head blight caused by Fusarium graminearum in wild emmer (Triticum dicoccoides) originating from Israel. Euphytica 130:17-23

Buerstmayr H, Ban T, Anderson JA (2009) QTL mapping and markerassisted selection for Fusarium head blight resistance in wheat: a review. Plant Breed 128:1-26

Buerstmayr H, Adam G, Lemmens ML (2012) Resistance to Head Blight Caused by Fusarium spp. in Wheat. In: Sharma I (ed) Disease resistance in wheat. CABI, Wallingford, pp 236-276

Cuthbert PA, Somers DJ, Brule-Babel A (2007) Mapping of Fhb2 on chromosome 6BS: a gene controlling Fusarium head blight field resistance in bread wheat (Triticum aestivum L.). Theor Appl Genet 114:429-437

Dall'Asta C, Dall'Erta A, Mantovani P, Massi A, Galaverna G (2013) Occurrence of deoxynivalenol and deoxynivalenol-3-glucoside in durum wheat. World Mycotoxin J 6:83-91

De Saeger S, Van Egmond HP (2012) Special issue: masked mycotoxins foreword. World Mycotoxin J 5:203-206 
Del Blanco IA, Frohberg RC, Stack RW, Berzonsky WA, Kianian SF (2003) Detection of QTL linked to Fusarium head blight resistance in Sumai 3-derived North Dakota bread wheat lines. Theor Appl Genet 106:1027-1031

Dickson J, Johann H, Wineland G (1921) Second progress report on the Fusarium blight (scab) of wheat. Phytopathology, p 35

Dill-Macky R (2003) Inoculation methods and evaluation of Fusarium head blight resistance in wheat. In: Leonard KJ, Bushnell WR (eds) Fusarium head blight of wheat and barley. The American Phytopathological Society, St Paul, pp 184-210

Draeger R, Gosman N, Steed A, Chandler E, Thomsett M, Srinivasachary, Schondelmaier J, Buerstmayr H, Lemmens M, Schmolke M, Mesterhazy A, Nicholson P (2007) Identification of QTLs for resistance to Fusarium head blight, DON accumulation and associated traits in the winter wheat variety Arina. Theor Appl Genet 115:617-625

Eckard JT, Glover KD, Mergoum M, Anderson JA, Gonzalez-Hernandez JL (2015) Multiple Fusarium head blight resistance loci mapped and pyramided onto elite spring wheat $F h b 1$ backgrounds using an IBDbased linkage approach. Euphytica 204:63-79

Elias EM, Manthey FA, Stack RW, Kianian SF (2005) Breeding efforts to develop Fusarium head blight resistant durum wheat in North Dakota. In: Canty SM, Boring T, Wardwell J, Siler L, Ward RW (eds) Proceedings of the 2005 national fusarium head blight forum, Milwaukee, WI, 11-13 Dec. Michigan State University, East Lansing, pp 25-26

Fakhfakh MM, Yahyaoui A, Rezgui S, Elias EM, Daaloul A (2011) Inheritances of Fusarium head blight resistance in a cross involving local and exotic durum wheat cultivars. Crop Sci 51:2517-2524

Gilsinger J, Kong L, Shen X, Ohm H (2005) DNA markers associated with low Fusarium head blight incidence and narrow flower opening in wheat. Theor Appl Genet 110:1218-1225

Goswami RS, Kistler HC (2004) Heading for disaster: Fusarium graminearum on cereal crops. Mol Plant Pathol 5:515-525

Graham S, Browne RA (2009) Anther extrusion and fusarium head blight resistance in european wheat. J Phytopathol 157:580-582

Guo J, Zhang XL, Hou YL, Cai JJ, Shen XR, Zhou TT, Xu HH, Ohm HW, Wang HW, Li AF, Han FP, Wang HG, Kong LR (2015) Highdensity mapping of the major FHB resistance gene $F h b 7$ derived from Thinopyrum ponticum and its pyramiding with Fhb1 by marker-assisted selection. Theor Appl Genet 128:2301-2316

Häberle J, Schmolke M, Schweizer G, Korzun V, Ebmeyer E, Zimmermann G, Hartl L (2007) Effects of two major Fusarium head blight resistance QTL verified in a winter wheat backcross population. Crop Sci 47:1823-1831

He X, Singh PK, Duveiller E, Dreisigacker S, Singh RP (2013a) Development and characterization of International Maize and Wheat Improvement Center (CIMMYT) germplasm for Fusarium head blight resistance. In: Alconada TM, Chulze SN (eds) Fusarium Head Blight in Latin America pp 241-262

He X, Singh PK, Duveiller E, Schlang N, Dreisigacker S, Singh RP (2013a) Identification and characterization of international Fusarium head blight screening nurseries of wheat at CIMMYT, Mexico. Eur J Plant Pathol 136:123-134

He XY, Singh PK, Schlang N, Duveiller E, Dreisigacker S, Payne T, He ZH (2014) Characterization of Chinese wheat germplasm for resistance to Fusarium head blight at CIMMYT, Mexico. Euphytica 195: 383-395

He X, Bonnett D, Singh PK, Hyles J, Spielmeyer W, Dreisigacker S (2015) Advanced wheat breeding lines combining Fhbl and $\mathrm{Sr} 2$ in different genetic backgrounds. Proceedings of the 9th international wheat conference, Sydney, Australia. p 140

He X, Lillemo M, Shi J, Wu J, Bjornstad A, Belova T, Dreisigacker S, Duveiller E, Singh P (2016) QTL characterization of Fusarium head blight resistance in CIMMYT bread wheat line Soru\#1. Plos One 11, e0158052
Heffner EL, Sorrells ME, Jannink JL (2009) Genomic selection for crop improvement. Crop Sci 49:1-12

Hilton AJ, Jenkinson P, Hollins TW, Parry DW (1999) Relationship between cultivar height and severity of Fusarium ear blight in wheat. Plant Pathol 48:202-208

Hoffstetter A, Cabrera A, Sneller C (2016a) Identifying quantitative trait loci for economic traits in an elite soft red winter wheat population. Crop Sci 56:547-558

Hoffstetter A, Cabrera A, Huang M, Sneller C (2016b) Optimizing training population data and validation of genomic selection for economic traits in soft winter wheat. G3 early online doi:10.1534 /g3.116.032532

Holzapfel J, Voss HH, Miedaner T, Korzun V, Haberle J, Schweizer G, Mohler V, Zimmermann G, Hartl L (2008) Inheritance of resistance to Fusarium head blight in three European winter wheat populations. Theor Appl Genet 117:1119-1128

Huhn MR, Elias EM, Ghavami F, Kianian SF, Chao SM, Zhong SB, Alamri MS, Yahyaoui A, Mergoum M (2012) Tetraploid tunisian wheat Germplasm as a new source of Fusarium head blight resistance. Crop Sci 52:136-145

Jiang GL, Dong Y, Shi J, Ward RW (2007a) QTL analysis of resistance to Fusarium head blight in the novel wheat germplasm CJ 9306. II. Resistance to deoxynivalenol accumulation and grain yield loss. Theor Appl Genet 115:1043-1052

Jiang GL, Shi JR, Ward RW (2007b) QTL analysis of resistance to Fusarium head blight in the novel wheat germplasm CJ 9306. I. Resistance to fungal spread. Theor Appl Genet 116:3-13

Jiang Y, Zhao Y, Rodemann B, Plieske J, Kollers S, Korzun V, Ebmeyer E, Argillier O, Hinze M, Ling J, Roder MS, Ganal MW, Mette MF, Reif JC (2015) Potential and limits to unravel the genetic architecture and predict the variation of Fusarium head blight resistance in European winter wheat (Triticum aestivum L.). Heredity 114:318326

Juroszek P, von Tiedemann A (2015) Linking plant disease models to climate change scenarios to project future risks of crop diseases: a review. J Plant Dis Protection 122:3-15

Kishii M, Ban T, Ammar K (2005) Improvement of FHB resistance of durum wheat. In: Canty M, Boring T, Wardwell J, Siler L, Ward RW (eds) Proc 2005 National Fusarium Head Blight Forum. Milwaukee, WI, 11-13 Dec 2005. Michigan State University, East Lansing, p 52

Kubo K, Kawada N, Fujita M, Hatta K, Oda S, Nakajima T (2010) Effect of cleistogamy on Fusarium head blight resistance in wheat. Breed Sci 60:405-411

Kubo K, Fujita M, Kawada N, Nakajima T, Nakamura K, Maejima H, Ushiyama T, Hatta K, Matsunaka H (2013) Minor differences in anther extrusion affect resistance to Fusarium head blight in wheat. J Phytopathol 161:308-314

Langer SM, Longin CFH, Wurschum T (2014) Phenotypic evaluation of floral and flowering traits with relevance for hybrid breeding in wheat (Triticum aestivum L.). Plant Breed 133:433-441

Lemmens M, Scholz U, Berthiller F, Dall'Asta C, Koutnik A, Schuhmacher R, Adam G, Buerstmayr H, Mesterhazy A, Krska R, Ruckenbauer P (2005) The ability to detoxify the mycotoxin deoxynivalenol colocalizes with a major quantitative trait locus for fusarium head blight resistance in wheat. Mol Plant-Microbe Interact 18:1318-1324

Lemmens M, Steiner B, Sulyok M, Nicholson P, Mesterhazy A, Buerstmayr H (2016) Masked mycotoxins: does breeding for enhanced Fusarium head blight resistance result in more deoxynivalenol-3-glucoside in new wheat varieties? World Mycotoxin J. doi:10.3920/WMJ2015.2029

Li X, Shin S, Heinen S, Dill-Macky R, Berthiller F, Nersesian N, Clemente T, McCormick S, Muehlbauer GJ (2015) Transgenic wheat expressing a barley UDP-Glucosyltransferase detoxifies Deoxynivalenol and provides high levels of resistance to Fusarium graminearum. Mol Plant-Microbe Interact 28:1237-1246 
Liu SX, Pumphrey MO, Gill BS, Trick HN, Zhang JX, Dolezel J, Chalhoub B, Anderson JA (2008) Toward positional cloning of Fhb1, a major QTL for Fusarium head blight resistance in wheat. Cereal Res Commun 36:195-201

Liu SY, Hall MD, Griffey CA, McKendry AL (2009) Meta-analysis of QTL associated with Fusarium head blight resistance in wheat. Crop Sci 49:1955-1968

Löffler M, Schön CC, Miedaner T (2009) Revealing the genetic architecture of FHB resistance in hexaploid wheat (Triticum aestivum L.) by QTL meta-analysis. Mol Breed 23:473-488

Lu QX, Lillemo M, Skinnes H, He XY, Shi JR, Ji F, Dong YH, Bjornstad A (2013) Anther extrusion and plant height are associated with Type I resistance to Fusarium head blight in bread wheat line 'Shanghai-3/ Catbird'. Theor Appl Genet 126:317-334

Maloney PV, Petersen S, Navarro RA, Marshall D, McKendry AL, Costa JM, Murphy JP (2014) Digital image analysis method for estimation of Fusarium-damaged kernels in wheat. Crop Sci 54:2077-2083

Mao SL, Wei YM, Cao W, Lan XJ, Yu M, Chen ZM, Chen GY, Zheng YL (2010) Confirmation of the relationship between plant height and Fusarium head blight resistance in wheat (Triticum aestivum L.) by QTL meta-analysis. Euphytica 174:343-356

McCartney CA, Somers DJ, Fedak G, DePauw RM, Thomas J, Fox SL, Humphreys DG, Lukow O, Savard ME, McCallum BD, Gilbert J, Cao W (2007) The evaluation of FHB resistance QTLs introgressed into elite Canadian spring wheat germplasm. Mol Breed 20:209221

McMullen M, Bergstrom G, De Wolf E, Dill-Macky R, Hershman D, Shaner G, Van Sanford D (2012) A unified effort to fight an enemy of wheat and barley: Fusarium head blight. Plant Dis 96:1712-1728

Mesterhazy A (1995) Types and components of resistance to Fusarium head blight of wheat. Plant Breed 114:377-386

Miedaner T, Reinbrecht C, Lauber U, Schollenberger M, Geiger HH (2001) Effects of genotype and genotype-enviromment interaction on deoxynivalenol accumulation and resistance to Fusarium head blight in rye, triticale, and wheat. Plant Breed 120:97-105

Miedaner T, Wilde F, Steiner B, Buerstmayr H, Korzun V, Ebmeyer E (2006) Stacking quantitative trait loci (QTL) for Fusarium head blight resistance from non-adapted sources in an European elite spring wheat background and assessing their effects on deoxynivalenol (DON) content and disease severity. Theor Appl Genet 112:562-569

Miedaner T, Wurschum T, Maurer HP, Korzun V, Ebmeyer E, Reif JC (2011) Association mapping for Fusarium head blight resistance in European soft winter wheat. Mol Breed 28:647-655

Mirdita V, He S, Zhao YS, Korzun V, Bothe R, Ebmeyer E, Reif JC, Jiang $Y$ (2015) Potential and limits of whole genome prediction of resistance to Fusarium head blight and Septoria tritici blotch in a vast Central European elite winter wheat population. Theor Appl Genet 128:2471-2481

Oliver RE, Stack RW, Miller JD, Cai X (2007) Reaction of wild emmer wheat accessions to Fusarium head blight. Crop Sci 47:893-899

Oliver RE, Cal X, Friesen TL, Halley S, Stack RW, Xu SS (2008) Evaluation of fusarium head blight resistance in tetraploid wheat (Triticum turgidum L.). Crop Sci 48:213-222

Osman M, He X, Singh RP, Duveiller E, Lillemo M, Pereyra SA, Westerdijk-Hoks I, Kurushima M, Yau S-K, Benedettelli S, Singh PK (2015) Phenotypic and genotypic characterization of CIMMYT's 15th international Fusarium head blight screening nursery of wheat. Euphytica 205:521-537

Parry DW, Jenkinson P, McLeod L (1995) Fusarium ear blight (scab) in small-grain cereals - a review. Plant Pathol 44:207-238

Pestka JJ (2010) Toxicological mechanisms and potential health effects of deoxynivalenol and nivalenol. World Mycotoxin J 3:323-347

Poppenberger B, Berthiller F, Lucyshyn D, Sieberer T, Schuhmacher R, Krska R, Kuchler K, Glossl J, Luschnig C, Adam G (2003) Detoxification of the Fusarium mycotoxin deoxynivalenol by a
UDP-glucosyltransferase from Arabidopsis thaliana. J Biol Chem 278:47905-47914

Prat N, Buerstmayr M, Steiner B, Robert O, Buerstmayr H (2014) Current knowledge on resistance to Fusarium head blight in tetraploid wheat. Mol Breed 34:1689-1699

Prat N, Guilbert C, Prah U, Wachter E, Steiner B, Langin T, Robert O, Buerstmayr H (2016) QTL mapping of Fusarium head blight resistance in three related durum wheat populations. Theor Appl Genet. doi:10.1007/s00122-016-2785-0

Pugh GW, Johann H, Dickson JG (1933) Factors affecting infection of wheat heads by Gibberella saubinetii. J Agric Res 46:771-779

Rawat N, Pumphrey MO, Liu S, Zhang X, Tiwari WK, Ando K, Trick HN, Bockus WW, Akhunov E, Anderson JA, Gill BS (2016) Wheat Fhb1 encodes a chimeric lectin with agglutinin domains and a poreforming toxin-like domain conferring resistance to Fusarium head blight. Nat Genet. doi:10.1038/ng.3706

Rutkoski J, Benson J, Jia Y, Brown-Guedira G, Jannink JL, Sorrells M (2012) Evaluation of genomic prediction methods for Fusarium head blight resistance in wheat. Plant Genome 5:51-61

Rychlik M, Humpf HU, Marko D, Danicke S, Mally A, Berthiller F, Klaffke H, Lorenz N (2014) Proposal of a comprehensive definition of modified and other forms of mycotoxins including "masked" mycotoxins. Mycotoxin Res 30:197-205

Salameh A, Buerstmayr M, Steiner B, Neumayer A, Lemmens M, Buerstmayr H (2011) Effects of introgression of two QTL for fusarium head blight resistance from Asian spring wheat by markerassisted backcrossing into European winter wheat on fusarium head blight resistance, yield and quality traits. Mol Breed 28:485-494

Schroeder HW, Christensen JJ (1963) Factors affecting resistance of wheat to scab caused by Gibberella zeae. Phytopathology 53:83138

Schweiger W, Steiner B, Vautrin S, Nussbaumer TGS, Zamini M, Jungreithmeier F, Gratl V, Lemmens M, Mayer K, Bérgès H, Adam G, Buerstmayr H (2016) Suppressed recombination and unique candidate genes in the divergent haplotype encoding Fhbl, a major Fusarium head blight resistance locus in wheat. Theor Appl Genet 129:1607-1623

Shi JR, Xu DH, Yang HY, Lu QX, Ban T (2008) DNA marker analysis for pyramided of Fusarium head blight (FHB) resistance QTLs from different germplasm. Genetica 133:77-84

Skinnes H, Tarkegne Y, Dieseth JA, Bjornstad A (2008) Associations between anther extrusion and Fusarium Head Blight in European wheat. Cereal Res Commun 36:223-231

Skinnes H, Semagn K, Tarkegne Y, Maroy AG, Bjornstad A (2010) The inheritance of anther extrusion in hexaploid wheat and its relationship to Fusarium head blight resistance and deoxynivalenol content. Plant Breed 129:149-155

Smith WG (1884) Diseases of field and garden crops. MacMillan and Co, London, pp 208-213

Srinivasachary, Gosman N, Steed A, Simmonds J, Leverington-Waite M, Wang Y, Snape J, Nicholson P (2008) Susceptibility to Fusarium head blight is associated with the Rht-Dlb semi-dwarfing allele in wheat. Theor Appl Genet 116:1145-1153

Srinivasachary, Gosman N, Steed A, Hollins TW, Bayles R, Jennings P, Nicholson P (2009) Semi-dwarfing Rht-Bl and Rht-Dl loci of wheat differ significantly in their influence on resistance to Fusarium head blight. Theor Appl Genet 118:695-702

von der Ohe C, Ebmeyer E, Korzun V, Miedaner T (2010) Agronomic and quality performance of winter wheat backcross populations carrying non-adapted Fusarium head blight resistance QTL. Crop Sci 50:2283-2290

Voss HH, Holzapfel J, Hartl L, Korzun V, Rabenstein F, Ebmeyer E, Coester H, Kempf H, Miedaner T (2008) Effect of the Rht-Dl dwarfing locus on Fusarium head blight rating in three segregating populations of winter wheat. Plant Breed 127:333-339 
Waldron BL, Moreno-Sevilla B, Anderson JA, Stack RW, Frohberg RC (1999) RFLP mapping of QTL for fusarium head blight resistance in wheat. Crop Sci 39:805-811

Warth B, Fruhmann P, Wiesenberger G, Kluger B, Sarkanj B, Lemmens M, Hametner C, Frohlich J, Adam G, Krska R, Schuhmacher R (2015) Deoxynivalenol-sulfates: identification and quantification of novel conjugated (masked) mycotoxins in wheat. Anal Bioanal Chem 407:1033-1039

Wilde F, Korzun V, Ebmeyer E, Geiger HH, Miedaner T (2007) Comparison of phenotypic and marker-based selection for Fusarium head blight resistance and DON content in spring wheat. Mol Breed 19:357-370

Xue SL, Li GQ, Jia HY, Xu F, Lin F, Tang MZ, Wang Y, An X, Xu HB, Zhang LX, Kong ZX, Ma ZQ (2010) Fine mapping Fhb4, a major QTL conditioning resistance to Fusarium infection in bread wheat (Triticum aestivum L.). Theor Appl Genet 121:147-156

Xue SL, Xu F, Tang MZ, Zhou Y, Li GQ, An X, Lin F, Xu HB, Jia HY, Zhang LX, Kong ZX, Ma ZQ (2011) Precise mapping Fhb5, a major QTL conditioning resistance to Fusarium infection in bread wheat (Triticum aestivum L.). Theor Appl Genet 123:1055-1063
Yang ZP, Gilbert J, Somers DJ, Fedak G, Procunier JD, McKenzie IH (2003) Marker assisted selection of Fusarium head blight resistance genes in two doubled haploid populations of wheat. Mol Breed 12:309-317

Zhang Q, Axtman JE, Faris JD, Chao S, Zhang Z, Friesen TL, Zhong S, Cai X, Elias EM, Xu SS (2014) Identification and molecular mapping of quantitative trait loci for Fusarium head blight resistance in emmer and durum wheat using a single nucleotide polymorphismbased linkage map. Mol Breed 34:1677-1687

Zhang X, Rouse MN, Nava IC, Jin Y, Anderson JA (2016) Development and verification of wheat germplasm containing both $\mathrm{Sr} 2$ and $F h b 1$. Mol Breed 36:85

Zhou WC, Kolb FL, Bai GH, Domier LL, Boze LK, Smith NJ (2003) Validation of a major QTL for scab resistance with SSR markers and use of marker-assisted selection in wheat. Plant Breed 122:40-46

Zhu XW, Zhong SB, Cai X (2016a) Effects of D-genome chromosomes and their A/B-genome homoeologs on Fusarium head blight resistance in durum wheat. Crop Sci 56:1-10

Zhu XW, Zhong SB, Chao SM, Gu YQ, Kianian SF, Elias E, Cai XW (2016b) Toward a better understanding of the genomic region harboring Fusarium head blight resistance QTL Qfhs.ndsu-3AS in durum wheat. Theor Appl Genet 129:31-43 